\title{
Automated characterization of anthropomorphicity of prosthetic feet fitted to bone-anchored transtibial prosthesis
}

\author{
Laurent Frossard $^{(1)}$, Barry Leech ${ }^{(2)}$, Mark Pitkin Author ${ }^{(3,4)}$ \\ (1) Queensland University of Technology, Brisbane, Australia \\ ${ }^{(2)}$ Barry Leech Prosthetics \& Orthotics Pty Ltd, Southport, Australia \\ (3) Tufts University, Boston, MA, USA and \\ (4) Poly-Orth International, Sharon, MA, USA (e-mail: mpitkin@tuftsmedicalcenter.org).
}

\begin{abstract}
Manuscript as published in "Frossard L, Leech B, Pitkin M. Automated characterization of anthropomorphicity of prosthetic feet fitted to bone-anchored transtibial prosthesis. IEEE Transactions on Biomedical Engineering. 2019. IEEEEXplore-DOI: 10.1109/TBME.2019.2904713."

https://ieeexplore.ieee.org/document/8666754
\end{abstract}

\begin{abstract}
Objective: This study describes differentiating prosthetic feet designs fitted to bone-anchored transtibial prostheses based on an automated characterization of ankle stiffness profile relying on direct loading measurements. The objectives were $(A)$ to present a process characterizing stiffness using innovative macro, meso and micro analyses, (B) to present stiffness profiles for feet with and without anthropomorphic designs, where anthropomorphicity is defined as a similarity of the moment-angle dependency in prosthetic and in the anatomical ankle, (C) to determine sensitivity of characterization.

Methods: Three participants walked consecutively with two instrumented bone-anchored prostheses including their own prosthetic feet and Free-Flow foot meeting the anthropomorphicity criterion by design. Angle of dorsiflexion was extracted from video footage. Bending moment was recorded using multi-axis transducer attached to osseointegrated fixation. The automated characterization of stiffness involved a 12-step process relying on data-based criterion.

Results: The meso analyses confirmed bilinear behavior of moment-angle curves with Index of Anthropomorphicity of $\mathbf{- 2 . 9 6 6 \pm 2 . 3 6 9} \mathrm{Nm} / \mathrm{Deg}$ and $\mathbf{2 . 6 8 1} \pm \mathbf{1 . 0 8 9} \mathrm{Nm} / \mathrm{Deg}$ indicating a convex and concave shape of usual and Free-Flow feet without and with anthropomorphic designs, respectively.

Conclusions: The proposed straightforward meso analysis of the stiffness was capable to report clinical meaningful differences sensitive to feet's anthropomorphicity. Results confirmed the benefits for clinicians to rely on direct loading measurement providing individualized complementary insight into impact of components.

Significance: This work could assist the developments of standards and guidelines for manufacturing and safe fitting of components to growing population requiring transtibial prostheses with socket or direct skeletal attachment worldwide..
\end{abstract}

Keywords

Amputation; Artificial limb; Bone-anchored prosthesis; Direct skeletal attachment; Osseointegrated implants; Osseointegration; Prosthesis; Loading; Kinetics; Feet; Stiffness

\section{INTRODUCTION}

Combined efforts from prosthetic care providers, including engineers and practitioners, to restore functional outcomes of individuals with lower limb amputation could be supported by in-depth biomechanical understanding of healthy joints. ${ }^{[1,2]}$ For instance, Drevelle et al (2014) indicated that "The stiffness related to flexion movement has been proposed to characterise the functioning of the healthy ankle and to define realistic targets for prosthesis design". ${ }^{[3]}$ This pointed out the importance of the ankle stiffness of a prosthetic foot in restoring functions. ${ }^{[4,}$ 5] Consequently, evidencing ankle stiffness is essential to support clinical decision and prescription of a given foot, particularly when fitted to a transtibial prosthesis. ${ }^{[6]}$

\section{A. Characterization of ankle stiffness}

Ankle stiffness of a prosthetic foot is conventionally represented by a curve showing the progression of angle of dorsiflexion in relation to the bending moment at the ankle joint over the flat foot phase of a gait cycle (GC). ${ }^{[3,7-12]}$ A linear curve indicates a constant stiffness. However, typical moment-angle curve of prosthetic feet have either a convex or concave shape associated with or 
without anthropomorphic ankle joint design, respectively. ${ }^{[10-13]}$

Review of literature focusing on able-bodied as well as individuals with transtibial and transfemoral socket prostheses revealed that the ankle momentangle curve of a prosthetic foot could be gradually characterized at three levels:

- Macro analyses summarized the stiffness as the slope of the regression line of the whole moment-angle curve. ${ }^{[3,14]}$

- Meso analyses relied on bilinear behaviour of moment-angle curve and slopes of the regression lines of the curve after and before a point of curvature (PC) change. ${ }^{[3,}$ 14] Quantification of the criterion of anthropomorphicity described elsewhere could differentiate feet generating concave or convex moment-angle curves. ${ }^{[10-13]}$.

- Micro analyses represented stiffness by a series of instantaneous slopes of regression lines of successive sections of the moment-angle curve. ${ }^{[12]}$

\section{B. Importance of stiffness in transtibial prostheses}

By definition, stiffness in a prosthetic ankle expresses itself as resistance to angulation which is transmitted back to the residuum via traditional socket or osseointegrated fixation.

Previous studies have demonstrated that the moment-angle dependency of a prosthetic ankle fitted to socket-suspended transtibial prostheses affects prosthetic limb joints kinematics, loading and metabolic cost. $\left.{ }^{[7,}{ }^{15}, 16\right]$ Furthermore, we demonstrated that a prosthetic ankle generating concave moment-angle curve seen in anatomical ankle decreased noticeably pressure in the socket compared to prosthetic feet generating convex moment-angle curve. ${ }^{[8-10,13,15,17]}$

It is now commonly accepted that the development of osseointegration is, in part or in whole, associated with loading regimen directly translated from the ground to the fixation that strongly depends on ankle stiffness. [18-29] Therefore, better understanding of the impact of ankle stiffness on osseointegrated fixation could possibly contribute to reduce early loosening of fixation, mechanical failure of percutaneous and medullar parts of fixation, periprosthetic issues and infections that are yet to be fully satisfactorily resolved. ${ }^{[23,24,30-35]}$

Altogether, stiffness characterization might also assist in the development of specific guidelines for design and prescription of feet and ankle units for transtibial prostheses, the sole loading elements under the control of prosthetists that is also subjected to cost-benefit analyses by funders. ${ }^{[36,37]}$

\section{Limits to characterization of ankle stiffness}

Currently, systematic and consistent characterization the true ankle stiffness of a given foot fitted to socket-suspended or bone-anchored transtibial prosthesis is currently limited by several shortcomings.

The identification of the shape of the momentangle curve is done subjectively using eyeballing for manual selection of PC..$^{[3,14]}$ The reporting of stiffness is inconsistent between studies using several original outcomes for either macro, meso and micro analysis. ${ }^{[38-40]}$ Altogether, the lack of standard quantitative criteria to conduct and report stiffness might increase intra- and inter-rater variability within and between studies, hinder benchmarking of ankle components and limit metaanalyses of published studies.

The concavity of the stiffness curve indicates that the moment of resistance is low at the beginning of dorsiflexion, and then rapidly increases as dorsiflexion progresses up to the heeloff. A dependency of this shape is a component of ballistic synergy that allows the calf and thigh extensor muscles to work mostly in the eccentric contraction mode, which is more biomechanical compared to the concentric contraction mode, and protects leg bones from excessive bending moments. ${ }^{[41,42]}$

A simple quantification of the moment-angle relationship in healthy patients was suggested in Drevelle et al (2014) and Pillet et al (2014). ${ }^{[3,14]}$ The concavity of the graph was characterized by two stiffnesses $\mathrm{K} 1$ and $\mathrm{K} 2$, each stiffness defined as the ratio of the ankle flexion moment to the ankle flexion angle. As shown in Fig 1, K1 and K2 correspond to the slopes of the moment-angle graph in the initial and final states of dorsiflexion. In anatomically healthy gait, $\mathrm{K} 2$ is statistically greater than $\mathrm{K} 1$.

\section{* Fig $1 *$}

Here, we suggest complementing typical meso analyses by introducing an Index of Anthropomorphicity (IA), where IA = K2-K1, corresponding to the difference between the two slopes of the regression lines of the moment-angle curve.

To date, specific algorithm capable of automatically characterizing the stiffness at each level is yet to be developed.

Perhaps less critical is the limitation associated with recording of raw dynamics information required to extract ankle bending moment. Typically, ground reaction forces and moments are collected using floor-mounted force-plates. [43-46] Instrumentation of clinical walkways as well as stairs and ramps is possible but tedious and often costly. More importantly, the sole contact of each foot on a force-plate required for valid dynamic measurements is commonly achieved through personalized arrangement of the starting point 
and/or force-plate positioning to avoid targeting and/or repetitive recording of invalid trials. ${ }^{[4,44,47]}$ Alternatively, a wireless portable kinetic system including a tri-axial transducer embedded in the prosthesis could provide directly bending moment making stiffness assessment possibly somewhat more ecological. ${ }^{[25-27,45,46,48-60]}$

\section{Need for automated characterization of stiffness}

Altogether, there is a need for an automated characterisation of ankle stiffness of prosthetic feet relying on direct loading measurement that is relevant to engineers, clinicians and biomechanists for more consistent evidence-based design, fitting and assessments of transtibial socket-suspended prostheses and, perhaps more importantly, BAP. ${ }^{[11,}$

\section{E. Objectives}

The main purpose of this observational casecontrol series study was to test the hypothesis that an automated characterization of the ankle stiffness relying on direct loading measurement can differentiate feet with and without anthropomorphic designs.

The specific objectives were:

- To present a step-by-step process relying on set data-based criterion for an automated characterization of the shape and magnitude of the stiffness profile of a prosthetic foot featuring macro, meso including IA and micro analyses,

- To present individuals and grouped stiffness profiles for three participants walking with a BAP successively fitted with their own ankle/foot units (i.e., RUSH, Trias, Triton) and Free-Flow foot meeting the anthropomorphicity criterion by design. ${ }^{[8,15]}$

- To compare stiffness profiles between feet using minimum clinically important difference to determine sensitivity of levels of analysis to foot design.

\section{MATERIALS AND METHODS}

\section{A. Participants}

This study involved all Queensland-based individuals with unilateral TTA fitted with a BAP using a so-called arm-length recruitment strategy applied by local prosthetists. No exclusion criteria were applied for gender, age, weight and height or level of activity. The specific inclusion criterion included (A) having circa six centimetres clearance between the percutaneous part of the fixation and ankle joint to fit the transducer as well as being (B) fully rehabilitated for at least 18 months, (C) capable to walk $200 \mathrm{~m}$ independently with BAP and (D) free of pain and infection at the time of recording. Human research ethical approval was received from the research institution. Written consent was obtained from all participants.

\section{B. Apparatus}

Participants walked consecutively with two instrumented prostheses connected to percutaneous part of press-fit osseointegrated fixation that included a connector, a transducer attached with pyramidal adaptors, a pylon, either their own or Free-Flow prosthetic foot (Fig 2). A qualified prosthetist handled all aspects of prosthesis fitting. Each prosthesis was aligned as closely as possible to usual alignment.

A digital camera (Canon, IXUS, US) with of sampling frequency of $25 \mathrm{~Hz}$ captured videos to facilitate extraction of the angle of dorsiflexion at the prosthetic ankle joint. The center of the fixed field of view of the sagittal plane included the whole participant during a full gait cycle of the prosthetic side facing the camera.

A portable kinetic system (iPecsLab, RTC, US) including a tri-axial transducer set of $200 \mathrm{~Hz}$ sent wirelessly loading applied on the fixation to a receiver connected to a laptop nearby. The three components of forces and moments were measured with previously established accuracy better than 1 $\mathrm{N}$ and $1 \mathrm{Nm}$, respectively. ${ }^{[48,51,54,62,63]}$ The prosthetist fitted the transducer as closely as possible to the percutaneous part so that its coordinate system was co-linear with anatomical axes of the fixation (Fig 2). Illustrations of individual position of the transducer in relation to ankle joint will be presented in subsequent Data-InBrief publication.

* Fig $2 *$

\section{Recording}

First, the prosthetist set up and aligned the instrumented prosthesis with the transducer and selected foot. Then, participants took approximately $15 \mathrm{~min}$ to acclimate with prostheses to ensure confidence and comfort before measurement. Next, participants were asked to perform five trials of level walking in straight-line on 5-meter walkway at self-selected comfortable pace, following protocol previously used for individuals with transfemoral BAP. ${ }^{[51,54,62]}$ Finally, the prosthesis was removed to allow benchtop calibration and removal of transducer (i.e., zerooffset).

\section{Processing}

The first primary outcomes were spatio-temporal gait characteristics. Raw video footage and loading data were imported, synchronized and processed in a customized Matlab software program (MathWorks Inc., MA, USA) allowing 
identification of a common heel contact $(\mathrm{HC})$ and toe off (TO). Manual detection of $\mathrm{HC}$ and TO events was achieved using vertical displacements of heel and toe of prosthetic foot as well as force applied the long axis of the fixation, respectively. These events were used to extract typical confounders of ankle stiffness including the cadence, duration of GC as well as duration of support and swing phases expressed in seconds and percentage of GC. ${ }^{[50]}$

The second primary outcome was the prosthetic ankle angle of dorsiflexion. Raw video footage were imported into a motion analysis software package (Kinovea) allowing manual selection of the angle projected in sagittal plane between the long axes of leg $\left(\mathrm{LG}_{\mathrm{L}}\right)$ and foot $\left(\mathrm{LG}_{\mathrm{F}}\right)$ intersecting at the ankle joint for each frame of the support phase with accuracy of approximately 2 Deg (Fig 2 ). The raw angles were tabulated into Matlab software program that calculated the final angle of dorsiflexion expressed in degree (e.g., raw angle-90 Deg).

The third primary outcome included the raw loading data initially imported in the Matlab program that were offset according to the magnitude of the load yielded during calibration. The bending moment was expressed in $\mathrm{Nm}$ without bodyweight normalisation and translation to ankle joint to report the actual range of loading and stiffness characteristics that could potentially be the most responsible for physiological development of osseointegration around the fixation. However, some bending moment information expressed in percentage of bodyweight will be presented in subsequent Data-In-Brief publication.

Both angle dorsiflexion and bending moment datasets were time normalized from 0 to 100 to facilitate averaging of trials and reporting of onset of events and durations in percentage of support (\%SUP).

\section{E. Characterization}

The series of secondary outcomes characterized the prosthetic ankle stiffness profile over each GC. The automated characterization relied on set databased criterion in each of the 12-step process as detailed in Table I.

The first six steps characterized the trochoid curvature of the moment-angle curve involving:

- Duration between relevant events occurring during flat foot phasis of the support corresponding the beginning and end of plantar flexion,

- Recognition of shape of the curve based on categorising each data points as "linear", "convex" or "concave" depending on their magnitude in relation to a reference line, and identification of the PC where the moment-angle curve changes angulation.
The last six steps extracted outcomes characterizing the magnitude of stiffness relying on:

- A macro analysis represented by K0 corresponding to the slope of the regression line of the whole moment-angle curve as reported in Drevelle et al (2014) and Pillet et al (2014), ${ }^{[3,14]}$

- A meso analysis represented by IA equal to the difference between $\mathrm{K} 2$ and $\mathrm{K} 1$ corresponding the slope of the regression line of moment-angle curve after and before $\mathrm{PC}$, so that an IA positive $(\mathrm{K} 1<\mathrm{K} 2)$ or negative $(\mathrm{K} 1>\mathrm{K} 2)$ confirmed a concave or convex shape as defined in Pitkin (2010), respectively. ${ }^{\text {[64] }}$

- A micro analysis including a series of $\mathrm{Ki}$ corresponding to instantaneous slopes of regression lines of pre-set successive sections of the moment-angle curve (e.g., every 4 points with a window of 3 points) as suggested in Pitkin (1996). ${ }^{[12]}$

Altogether, the stiffness profile was characterised by eight discrete outcomes (i.e., duration between $\mathrm{HC}$, TC, $\mathrm{HO}$ and $\mathrm{TO}$, onset of $\mathrm{PC}$, magnitude of K0, K1, K2 slopes, IA) and four continuous outcomes (i.e., percentage of data points characterised as "linear", "convex" or "concave", Ki).

\section{* Table I *}

\section{F. Comparative analysis}

Individual stiffness outcomes were averaged after collating trials from each participant $(\mathrm{N}=5$ for each participant). Grouped stiffness outcomes were averaged after collating all trials from three participants ( $\mathrm{N}=15$ for each prosthesis). Overall stiffness outcomes was achieved by extracting variables using the averaged grouped angle dorsiflexion and bending moment $(\mathrm{N}=1$ for each prosthesis).

Individual or intra-variability and grouped or inter-variability of a discrete stiffness outcomes were determined using the percentage of variation (PV= absolute [[standard deviation / mean] x100]). We considered than a PV inferior to $20 \%$ indicated a low variability.

The difference in discrete stiffness outcomes between feet was determined so that a positive difference indicated that Free-Flow foot was algebraically larger than usual foot. We considered that a difference superior to $10 \%$ was above a minimum clinically important difference (MCID). This threshold might appear low compared to other studies comparing prosthetic knee components suggesting that an MCID of $20 \%$ was relevant. ${ }^{[65]}$ We believe a lower MCID was justified in the particular case of individuals fitted transtibial BAP 
given their increase proprioception due to osseoperception provided by osseointegrated fixation. ${ }^{[66]}$

\section{RESULTS}

The demographic, amputation and prosthetic information for the two males (P1, P2) and one female (P3) who participated in study between May and July 2017 were summarized in Table II. The usual prostheses included a RUSH foot (RUSH, US) and running shoes, Trias 1C30 (Otto Bock, US) and running shoes as well as Triton - Vertical shock 1C6 (Otto Bock, US) for P1, P 2 and P3, respectively. Only $\mathrm{P} 2$ used a foot recommended for transfemoral BAP prostheses fitted to screw-type implant.[73] The direct skeletal attachment was achieved thanks to a surgical procedure involving a total knee replacement and implantation of press-fit osseointegrated fixation. ${ }^{[18]}$ All participants were active with an overall fairly high ambulatory capacity.

\section{* Table II *}

A total of 28 out of 30 GCs were analysed, including 14 with usual and Free-Flow feet as a trial with each prosthesis was unsuited for analysis due to technical glitch.

\section{A. Spatio-temporal gait characteristics}

As detailed in Table III, the individual cadence, duration of GC and support phases ranged from $40 \pm 1$ to $52 \pm 1$ strides/min, $1.158 \pm 0.02$ to $1.488 \pm 0.034 \mathrm{~s}$ and $61 \pm 1$ to $68 \pm 2 \% \mathrm{GC}$ with usual foot as well as $45 \pm 1$ to $51 \pm 1$ strides $/ \mathrm{min}$, $1.175 \pm 0.016$ to $1.46 \pm 0.029 \mathrm{~s}$ and $61 \pm 1$ to $64 \pm 2$ $\%$ GC with Free-Flow foot, respectively. All individual and grouped spatio-temporal characteristics presented a low intra- and intervariabilities. The difference was below MCID for all individual and grouped characteristics except for cadence, duration of GC and support phases in seconds for P1 as well as duration of swing for P3.

* Table III *

\section{B. Individual and grouped stiffness profile}

The shape and magnitude provided by macro and meso analyses of all individual and grouped stiffness profiles with both prostheses are presented in Table IV.

The individual stiffness profile with usual foot showed an onset of PC, percentage of data identified as convex, $\mathrm{K} 0$ and IA ranged from $34 \pm 3$ to $59 \pm 8 \%$ DUR, $74 \pm 29$ to $91 \pm 13 \%$ FLT, $2.901 \pm 0.337$ to $4.966 \pm 0.813 \mathrm{Nm} / \mathrm{Deg}$ and $1.978 \pm 1.477$ to $-4.423 \pm 1.670 \quad \mathrm{Nm} / \mathrm{Deg}$, respectively. The individual stiffness profile with Free-Flow foot showed an onset of PC, percentage of data identified as concave, $\mathrm{K} 0$ and IA ranged from $31 \pm 3$ to $38 \pm 7 \%$ DUR, $44 \pm 12$ to $80 \pm 10 \%$ FLT, $2.315 \pm 0.341$ to $2.910 \pm 0.403 \mathrm{Nm} / \mathrm{Deg}$ and $2.270 \pm 1.385$ to $3.319 \pm 0.679 \mathrm{Nm} / \mathrm{Deg}$, respectively.

Altogether, $15(47 \%)$ and $13(41 \%)$ of the individual and grouped discrete stiffness outcomes with usual and Free-Flow feet had low variability, respectively.

All the differences in duration between both prostheses were strongly above MCID except between TC and $\mathrm{HO}$ for P1, P3 and grouped. The differences in onset of PC were below MCID only for P2. The differences were strongly above MCID for all individual and grouped stiffness characteristics obtained with macro (e.g., K0) and meso analyses (i.e., K1, K2, IA).

\section{* Table IV *}

\section{Overall stiffness profile}

An overview of grouped angle of dorsiflexion and bending moment as well as shape and regression lines deriving from macro, meso and micro analyses of overall moment-angle curves with both prostheses are provided in Fig 3 .

With usual foot, the angle of dorsiflexion progressed by 18.54 Deg from -16.55 Deg to 2.00 Deg while the bending moment progressed by $74.73 \mathrm{Nm}$ from $-12.29 \mathrm{Nm}$ to $62.45 \mathrm{Nm}$ between TC and HO, respectively. Overall stiffness profile with usual foot revealed that the durations between $\mathrm{HC}, \mathrm{TC}, \mathrm{HO}$ and TO represented $14 \%, 70 \%$ and $16 \%$ of support; the PC occurred at $40 \%$ SUP; $100 \%$ of the data points was classified as convex; as well as K0, K1, K2 and IA were $4.150 \mathrm{Nm} / \mathrm{Deg}$, $5.220 \mathrm{Nm} / \mathrm{Deg}, \quad 3.298 \mathrm{Nm} / \mathrm{Deg}$ and -1.922 $\mathrm{Nm} /$ Deg, respectively.

With Free-Flow foot, the angle of dorsiflexion progressed by 22.27 Deg from -18.60 Deg to 3.67 Deg while the bending moment progressed by 60.21 Nm from $-8.28 \mathrm{Nm}$ to $51.94 \mathrm{Nm}$ between TC and $\mathrm{HO}$, respectively. Overall stiffness profile of Free-Flow foot revealed that the durations between $\mathrm{HC}, \mathrm{TC}, \mathrm{HO}$ and $\mathrm{TO}$ represented $12 \%, 64 \%$ and $24 \%$ of support; the PC occurred at $38 \%$ SUP; $3 \%$, $14 \%$ and $82 \%$ of data points were classified as linear, convex and concave; as well as $\mathrm{K} 0, \mathrm{~K} 1, \mathrm{~K} 2$ and IA were $2.758 \mathrm{Nm} / \mathrm{Deg}, 1.349 \mathrm{Nm} / \mathrm{Deg}, 4.401$ $\mathrm{Nm} /$ Deg and $3.052 \mathrm{Nm} /$ Deg, respectively.

Individual angle of dorsiflexion and bending moment as well as moment-angle curves will be presented in subsequent Data-In-Brief publication.

\section{* Fig $3 *$}

\section{DISCUSSION}

\section{A. Outcomes}

The results showed that the three usual feet could be classified as non-anthropomorphic accordingly 
to the proposed criterion (e.g., convex individual moment-angle curves, negative IA). As expected, both grouped onset of the PC $(46 \pm 12 \%$ SUP $)$ and IA $(-2.966 \pm 2.369 \mathrm{Nm} / \mathrm{Deg})$ had high intervariability more likely due to the range of usual feet used.

Equally, this study confirmed the anthropomorphic design of Free-Flow foot (e.g., concave individual moment-angle curves, positive IA in agreement with ${ }^{[3,14]}$ ). The onset of PC (36 $\pm 6 \%$ SUP) had low variability. However, IA $(2.681 \pm 1.089 \mathrm{Nm} / \mathrm{Deg})$ had high inter-variability that might be due to short acclimation time.

Differences of key stiffness outcomes above MCID between both prostheses could only be minimally explained by differences in spatiotemporal characteristics since differences in cadence were mostly below MCID.

Incidentally, the K1, K2 and IA obtained with Free-Flow foot were lower than the ones considered by Major et al (2014) when looking at the effects of prosthetic ankle stiffness on kinematics, dynamics and metabolic cost of individuals fitted with transtibial socket prostheses $(\mathrm{K} 1=[9,420 \mathrm{~N}-\mathrm{cm} / \mathrm{rad}=1.644 \mathrm{Nm} / \mathrm{Deg}, 20,280 \mathrm{~N}-$ $\mathrm{cm} / \mathrm{rad}=3.539 \quad \mathrm{Nm} / \mathrm{Deg}], \quad \mathrm{K} 2=[39,430 \quad \mathrm{~N}-$ $\mathrm{cm} / \mathrm{rad}=6.882 \mathrm{Nm} / \mathrm{Deg}, 139,570 \mathrm{~N}-\mathrm{cm} / \mathrm{rad}=24.359$ $\mathrm{Nm} / \mathrm{Deg}$ ], IA=[5.238 Nm/Deg, $20.820 \mathrm{Nm} / \mathrm{Deg}]$ ), as well as the ones reported by Drevelle et al (2014) and Pillet et al (2014) for asymptomatic participants ankle stiffness (i.e., $\mathrm{K} 1=0.06 \pm 0.02$ $\mathrm{Nm} . \mathrm{kg} / \mathrm{Deg}=4.26 \pm 1.42 \mathrm{Nm} / \mathrm{Deg}, \mathrm{K} 2=0.15 \pm 0.05$ $\mathrm{Nm} . \mathrm{kg} / \mathrm{Deg}=10.65 \pm 3.55 \mathrm{Nm} / \mathrm{Deg}, \mathrm{IA}=6.39 \pm 2.13$ $\mathrm{Nm} / \mathrm{Deg}) .^{[3,7,14]}$

Nonetheless, this initial benchmarking data tend to confirm the hypothesis that the proposed automated characterization of the ankle stiffness relying on direct loading measurement can differentiate feet with and without anthropomorphic designs fitted to transtibial BAP.

Furthermore, results showed the limitations of some commonly used analyses to determine the magnitude of the stiffness and report anthropomorphicity. The meso analysis provided a positive $\mathrm{K} 0$ for both feet. It was partially suitable mainly because all stiffness datapoints progressed around an upward diagonal line as described above. The micro analysis showed differences in $\mathrm{Ki}$ between feet. The fine tuning of window size was data processing intensive but this analysis is more likely to assist engineers in the design of components with variable stiffness over the support phase. The meso analysis and particularly the use of IA showed critical differences between feet. This analysis might be preferable in clinical context as it requires extraction of only two basic slopes (K1, K2) while reporting clinical meaningful information that reflect anthropomorphicity.

Finally, the results also highlighted the limitation of basic visual observations combining spatio- temporal and ankle joint angles only that were the least sensitive to difference in foot design. For instance, grouped angle of dorsiflexion progressed by $20.13 \pm 5.65$ Deg for usual feet and by $24.95 \pm 7.46$ Deg for Free-Flow feet. The dorsiflexion generated by Flee-Flow foot increased by $20 \%$ corresponding to only 4 Deg that is close to angle measurements errors. In contrast, the grouped bending moment progressed by $73.27 \pm 29.62 \mathrm{Nm}$ for usual feet and by $54.99 \pm 13.37 \mathrm{Nm}$ for FreeFlow feet. The bending moment generated by FleeFlow foot decreased by $25 \%$ corresponding to 18 $\mathrm{Nm}$ that is well and truly larger than load measurements errors. It is difficult to ascertain if an expert can visually discriminate differences of angles. Nonetheless, these results confirmed the benefits for clinicians to rely on direct loading measurements providing individualized complementary insight into bespoke impact of components.

\section{B. Limitations}

Interpretation of differences in stiffness outcomes between prostheses was limited mainly because of unknown effects of confounders such as individual length of residuum, variation of position of transducer in relation to ankle joint, lack of blinding, short acclimation with Free-Flow foot, effect of foot size and footwear, specific spatial gait characteristics (e.g., speed of walking, walking base, step and stride length), kinematics (e.g., trunk bending, knee flexion, hip range of movement) and kinetics (e.g., knees and hips joint power) information. ${ }^{[65]}$

By definition, the generalization of stiffness outcomes must be considered carefully giving the typical intrinsic shortcoming of a case-series study and limitations listed above. Nonetheless, this study provided initial benchmark stiffness profile involving $42 \%$ of existing population with transtibial amputation fitted with press-fit fixation worldwide.

More generalizable is the methodological contributions for a practical recording, analysis and reporting of ankle stiffness profile. Indeed, this information should be considered and, possibly, educate the design of subsequent studies focusing on characterization of transtibial BAP (e.g., purchase of equipment, recording settings, software development). For example, implementation of meso analysis might reduce noticeably computing time while producing relevant clinical outcomes.

\section{Future studies}

The proposed meso analysis will facilitate future longitudinal studies comparing prosthetic constructs (e.g., components, alignment) for a larger cohort of individuals fitted with a transtibial prosthesis. ${ }^{[40,}$ 67] This could provide a better understanding of intra- and inter-variability inherent to attachments (fixation vs socket), design 
of components, participants and daily activities. ${ }_{69]}^{[68,}$

Subsequent cross-sectional studies could establish a link between ankle stiffness outcomes and additional 3D biomechanical (e.g., dynamics, kinematics, joint work and power), physiological (e.g., EMG of residuum muscles, metabolic energy consumption, development of osseointegration, skin damages) and participants' experience (e.g., PEQm, TAPES-M) information.

\section{CONCLUSIONS}

An attempt to develop a comprehensive automated characterization of ankle stiffness profile for transtibial BAP was shared for the first time. This work was also an initial effort toward laying out characterization principles for stiffness analysis while providing benchmark of stiffness data using feet with and without anthropomorphic designs.

Altogether, this study should be considered as a stepping-stone for manufacturers of components and prosthetic care providers developing international standards and guidelines for fitting safely prosthetic components to growing population of individuals with transtibial amputation fitted socket or osseointegrated fixation worldwide.

\section{Abbreviations}

\%SUP: Percentage of support phases

BAP: Bone-anchored prosthesis

GC: Gait cycle

HC: Heel contact

HO: Heel-off

IA: Index of Anthropomorphicity

K0: Slope of whole moment-angle curve

K1: First slope of moment-angle curve

$\mathrm{K} 2$ : Second slope of moment-angle curve

$\mathrm{Ki}$ : Instantaneous slopes of the moment-angle curve

$\mathrm{LG}_{\mathrm{F}}$ : Long axis of the prosthetic foot

$\mathrm{LG}_{\mathrm{L}}$ : Long axis of the prosthetic leg

MCID: Minimum clinically important difference

$\mathrm{N}$ : Number of gait cycles

P: Participants (P1, P2, P3)

PC: Point of curvature

PV: Percentage of variation

SUP: Support phases of gait cycle

TC: Toe contact

TO: Toe off

\section{Acknowledgment}

The work solely conducted by L. Frossard focusing on the characterization of the stiffness profile related macro, meso and micro analyses was partially supported by the Office of the Assistant Secretary of Defense for Health Affairs, through the Orthotics and Prosthetics Outcomes Research
Program - Prosthetics Outcomes Research Award under Award No. W81XWH-16-1-0475. Opinions, interpretations, conclusions and recommendations are those of the author and are not necessarily endorsed by the Department of Defense.

The work solely conducted by M. Pitkin focusing on development of the moment criterion of anthropomorphicity and synthesis of the FreeFlow foot mechanism was supported in part by the National Institute of Arthritis and Musculoskeletal and Skin Diseases of the National Institutes of Health under Award Number AR43290

The authors wish to acknowledge Jim Colvin and the Ohio Willow Wood Company, Mt. Sterling, $\mathrm{OH}$, for providing the Free-Flow feet as well as Samantha Leech, Michele Mahoney from Barry Leech Prosthetics \& Orthotics Pty Ltd for their valuable contribution to organization of the data collection.

\section{References}

[1] K. Jalaleddini, E. S. Tehrani, and R. E. Kearney, "A Subspace Approach to the Structural Decomposition and Identification of Ankle Joint Dynamic Stiffness," IEEE Trans Biomed Eng, vol. 64, no. 6, pp. 1357-1368, Jun, 2017.

[2] A. F. Azocar, and E. J. Rouse, "Stiffness Perception During Active Ankle and Knee Movement," IEEE Trans Biomed Eng, vol. 64, no. 12, pp. 2949-2956, Dec, 2017.

[3] X. Drevelle, C. Villa, X. Bonnet et al., "Analysis of ankle stiffness for asymptomatic subjects and transfemoral amputees in daily living situations," Comput Methods Biomech Biomed Engin, vol. 17 Suppl 1, no. sup1, pp. 80-1, 2014/08/06, 2014.

[4] W. L. Childers, and K. Z. Takahashi, "Increasing prosthetic foot energy return affects whole-body mechanics during walking on level ground and slopes," Scientific Reports, vol. 8, no. 1, pp. 5354, 2018/03/29, 2018.

[5] P. G. Adamczyk, M. Roland, and M. E. Hahn, "Novel method to evaluate angular stiffness of prosthetic feet from linear compression tests," J Biomech Eng, vol. 135, no. 10, pp. 104502-5, Oct 1, 2013.

[6] H. van der Linde, C. J. Hofstad, A. C. Geurts et al., "A systematic literature review of the effect of different prosthetic components on human functioning with a lower-limb prosthesis," J Rehabil Res Dev, vol. 41, no. 4, pp. 555-70, Jul, 2004.

[7] M. J. Major, M. Twiste, L. P. Kenney et al., "The effects of prosthetic ankle stiffness on ankle and knee kinematics, prosthetic limb loading, and net metabolic cost of trans-tibial amputee gait," Clin 
Biomech (Bristol, Avon), vol. 29, no. 1, pp. 98-104, Jan, 2014.

[8] M. Pitkin, Artificial Foot and Ankle, U. P. 5376139, 1994.

[9] M. Pitkin, j. Hays, S. Srinivasan et al., Artificial foot and ankle, U. P. 6290730, 2001.

[10] M. Pitkin, "Anthropomorphicity of lower limb prostheses," Biomechanics of Lower Limb Prosthetics, B. Springer, Heidelberg, ed., 2010.

[11] P. M. Quesada, M. Pitkin, and J. Colvin, "Biomechanical evaluation of a prototype foot/ankle prosthesis," IEEE Trans Rehabil Eng, vol. 8, no. 1, pp. 156-9, Mar, 2000.

[12] M. R. Pitkin, "Synthesis of a cycloidal mechanism of the prosthetic ankle," Prosthet Orthot Int, vol. 20, no. 3, pp. 159-71, Dec, 1996.

[13] M. Pitkin, "Mechanical outcome of a rolling joint prosthetic foot, and its performance in dorsiflexion phase of the trans-tibial amputee gait," Journal of Prosthetics and Orthotics, vol. 7, no. 4, pp. 114-123, 1995.

[14] H. Pillet, X. Drevelle, X. Bonnet et al., "APSIC: Training and fitting amputees during situations of daily living," Irbm, vol. 35, no. 2, pp. 60-65, 2014/04/01/, 2014.

[15] M. R. Pitkin, "Effects of Design Variants in Lower-Limb Prostheses on Gait Synergy," J Prosthet Orthot, vol. 9, no. 3, pp. 113-122, Summer, 1997.

[16] K. E. Zelik, S. H. Collins, P. G. Adamczyk et al., "Systematic variation of prosthetic foot spring affects center-ofmass mechanics and metabolic cost during walking," IEEE Trans Neural Syst Rehabil Eng, vol. 19, no. 4, pp. 411-9, Aug, 2011.

[17] M. Pitkin, "Lowering the forces and pressures on amputee stump with Rolling Joint Foot," Biomecanics, vol. 315-318, 1999.

[18] A. Khemka, L. Frossard, S. J. Lord et al., "Osseointegrated total knee replacement connected to a lower limb prosthesis: 4 cases," Acta Orthop, pp. 1-5, Aug 27, 2015.

[19] T. Kobayashi, M. S. Orendurff, M. Zhang et al., "Effect of transtibial prosthesis alignment changes on out-of-plane socket reaction moments during walking in amputees," J Biomech, vol. 45, no. 15, pp. 2603-9, Oct 11, 2012.

[20] D. A. Boone, T. Kobayashi, T. G. Chou et al., "Influence of malalignment on socket reaction moments during gait in amputees with transtibial prostheses," Gait Posture, vol. 37, no. 4, pp. 620-6, Apr, 2013.

[21] T. Kobayashi, M. S. Orendurff, M. Zhang et al., "Effect of alignment changes on sagittal and coronal socket reaction moment interactions in transtibial prostheses," J Biomech, vol. 46, no. 7, pp. 1343-50, Apr 26, 2013.

[22] P. Stenlund, M. Trobos, J. Lausmaa et al., "Effect of load on the bone around boneanchored amputation prostheses," $J$ Orthop Res, vol. 35, no. 5, pp. 1113-1122, May, 2017.

[23] B. Helgason, H. Palsson, T. P. Runarsson et al., "Risk of failure during gait for direct skeletal attachment of a femoral prosthesis: a finite element study," Med Eng Phys, vol. 31, no. 5, pp. 595-600, Jun, 2009.

[24] W. C. Lee, J. M. Doocey, R. Branemark et al., "FE stress analysis of the interface between the bone and an osseointegrated implant for amputees--implications to refine the rehabilitation program," Clin Biomech (Bristol, Avon), vol. 23, no. 10, pp. 1243-50, Dec, 2008.

[25] S. Vertriest, P. Coorevits, K. Hagberg et al., "Static load bearing exercises of individuals with transfemoral amputation fitted with an osseointegrated implant: reliability of kinetic data," IEEE Trans Neural Syst Rehabil Eng, vol. 23, no. 3, pp. 423-30, May, 2015.

[26] L. Frossard, K. Hagberg, E. Haggstrom et al., "Load-relief of walking aids on osseointegrated fixation: instrument for evidence-based practice," IEEE Trans Neural Syst Rehabil Eng, vol. 17, no. 1, pp. 9-14, Feb, 2009.

[27] S. Vertriest, P. Coorevits, K. Hagberg et al., "Static load bearing exercises of individuals with transfemoral amputation fitted with an osseointegrated implant: Loading compliance," Prosthet Orthot Int, vol. 41, no. 4, pp. 393-401, Aug, 2017.

[28] M. Pitkin, "Design features of implants for direct skeletal attachment of limb prostheses," J Biomed Mater Res A, vol. 101, no. 11, pp. 3339-48, Nov, 2013.

[29] M. Pitkin, "One lesson from arthroplasty to osseointegrationin search for better fixation of in-bone implanted prosthesis," Journal of Rehabilitation Research \& Development, vol. 45, no. 4, pp. 6-14, 2008.

[30] M. Lenneras, G. Tsikandylakis, M. Trobos et al., "The clinical, radiological, microbiological and molecular profile of the skin-penetration site of transfemoral amputees treated with bone-anchored 
prostheses," J Biomed Mater Res A, pp. n/a-n/a, Oct 17, 2016.

[31] S. K. Kunutsor, D. Gillatt, and A. W. Blom, "Systematic review of the safety and efficacy of osseointegration prosthesis after limb amputation," BJS, vol. 0, no. 0, 2018.

[32] R. Atallah, R. A. Leijendekkers, T. J. Hoogeboom et al., "Complications of bone-anchored prostheses for individuals with an extremity amputation: A systematic review," PLoS One, vol. 13, no. 8, pp. e0201821, 2018.

[33] A. Maryniak, B. Laschowski, and J. Andrysek, "Technical Overview of Osseointegrated Transfemoral Prostheses: Orthopaedic Surgery and Implant Design Centered," Journal of Engineering and Science in Medical Diagnostics and Therapy, 2018.

[34] J. S. Hebert, M. Rehani, and R. Stiegelmar, "Osseointegration for LowerLimb Amputation: A Systematic Review of Clinical Outcomes," JBJS Reviews, vol. 5, no. 10, pp. e10, 2017.

[35] R. A. Leijendekkers, G. van Hinte, J. P. Frolke et al., "Comparison of boneanchored prostheses and socket prostheses for patients with a lower extremity amputation: a systematic review," Disabil Rehabil, vol. 39, no. 11, pp. 1045-1058, Jun, 2017.

[36] L. Frossard, D. Berg, G. Merlo et al., "Cost Comparison of Socket-Suspended and Bone-Anchored Transfemoral Prostheses," Journal of Prosthetics and Orthotics, vol. 29, no. 4, pp. 150-160, 2017.

[37] L. Frossard, G. Merlo, T. Quincey et al., "Development of a Procedure for the Government Provision of Bone-Anchored Prosthesis Using Osseointegration in Australia," Pharmacoecon Open, vol. 1, no. 4, pp. 301-314, Dec, 2017.

[38] W. C. Lee, M. Zhang, P. P. Chan et al., "Gait analysis of low-cost flexible-shank transtibial prostheses," IEEE Trans Neural Syst Rehabil Eng, vol. 14, no. 3, pp. 370-7, Sep, 2006.

[39] B. C. Glaister, J. A. Schoen, M. S. Orendurff et al., "Mechanical behavior of the human ankle in the transverse plane while turning," IEEE Trans Neural Syst Rehabil Eng, vol. 15, no. 4, pp. 552-9, Dec, 2007.

[40] J. Gardiner, A. Z. Bari, L. Kenney et al., "Performance of Optimized Prosthetic Ankle Designs That Are Based on a Hydraulic Variable Displacement Actuator (VDA)," IEEE Trans Neural Syst Rehabil
Eng, vol. 25, no. 12, pp. 2418-2426, Dec, 2017.

[41] M. Pitkin, "Ballistic synergy in Normal Gait, in:," Biomechanics of lower limb prosthetics, pp. 39-52, Heidelberg, Dondrecht, London, New York: Springer, 2010.

[42] J. Perry, Gait Analysis: normal and pathological function, Thorofare, $\mathrm{NJ}$ : Slack, Inc., 1992.

[43] R. Dumas, R. Branemark, and L. Frossard, "Gait Analysis of Transfemoral Amputees: Errors in Inverse Dynamics Are Substantial and Depend on Prosthetic Design," IEEE Trans Neural Syst Rehabil Eng, vol. 25, no. 6, pp. 679-685, Jun, 2017.

[44] L. Frossard, L. Cheze, and R. Dumas, "Dynamic input to determine hip joint moments, power and work on the prosthetic limb of transfemoral amputees: ground reaction vs knee reaction," Prosthet Orthot Int, vol. 35, no. 2, pp. 140-9, Jun, 2011.

[45] L. Frossard, N. Stevenson, J. Sullivan et al., "Categorization of Activities of Daily Living of Lower Limb Amputees During Short-Term Use of a Portable Kinetic Recording System: A Preliminary Study," Journal of Prosthetics and Orthotics, vol. 23, no. 1, pp. 2-11, 2011.

[46] L. Frossard, N. Stevenson, J. Smeathers et al., "Monitoring of the load regime applied on the osseointegrated fixation of a trans-femoral amputee: a tool for evidence-based practice," Prosthet Orthot Int, vol. 32, no. 1, pp. 68-78, Mar, 2008.

[47] R. Dumas, L. Cheze, and L. Frossard, "Loading applied on prosthetic knee of transfemoral amputee: comparison of inverse dynamics and direct measurements," Gait Posture, vol. 30, no. 4, pp. 560-2, Nov, 2009.

[48] L. Frossard, J. Beck, M. Dillon et al., "Development and preliminary testing of a device for the direct measurement of forces and moments in the prosthetic limb of transfemoral amputees during activities of daily living," Journal of Prosthetics and Orthotics, vol. 15, no. 4, pp. 135-142, 2003.

[49] L. Frossard, D. L. Gow, K. Hagberg et al., "Apparatus for monitoring load bearing rehabilitation exercises of a transfemoral amputee fitted with an osseointegrated fixation: a proof-of-concept study," Gait Posture, vol. 31, no. 2, pp. 223-8, Feb, 2010.

[50] L. Frossard, K. Hagberg, E. Häggström et al., "Functional Outcome of Transfemoral 
Amputees Fitted With an Osseointegrated Fixation: Temporal Gait Characteristics," Journal of Prosthetics and Orthotics, vol. 22, no. 1, pp. 11-20, 2010.

[51] L. Frossard, E. Haggstrom, K. Hagberg et al., "Load applied on a bone-anchored transfemoral prosthesis: characterisation of prosthetic components - A case study" Journal of Rehabilitation Research \& Development, vol. 50, no. 5, pp. 619-634, 2013.

[52] L. Frossard, R. Tranberg, E. Haggstrom et al., "Fall of a transfemoral amputee fitted with osseointegrated fixation: loading impact on residuum," Gait \& Posture, vol. 30, no. Supplement 2, pp. S151-S152, 2009.

[53] L. A. Frossard, "Load on osseointegrated fixation of a transfemoral amputee during a fall: Determination of the time and duration of descent," Prosthet Orthot Int, vol. 34, no. 4, pp. 472-87, Dec, 2010.

[54] W. Lee, L. Frossard, K. Hagberg et al., "Magnitude and variability of loading on the osseointegrated implant of transfemoral amputees during walking," Med Eng Phys, vol. 30, no. 7, pp. 825-833, Sep, 2008.

[55] W. C. Lee, L. A. Frossard, K. Hagberg et al., "Kinetics of transfemoral amputees with osseointegrated fixation performing common activities of daily living," Clin Biomech (Bristol, Avon), vol. 22, no. 6, pp. 665-73, Jul, 2007.

[56] S. Pather, S. Vertriest, P. Sondergeld et al., "Load characteristics following transfemoral amputation in individuals fitted with bone-anchored prostheses: a scoping review protocol," JBI Database System Rev Implement Rep, vol. 16, no. 6, pp. 1286-1310, Jun, 2018.

[57] E. S. Neumann, J. Brink, K. Yalamanchili et al., "Use of a Load Cell and ForceMoment Analysis to Examine Transtibial Prosthesis Foot Rollover Kinetics for Anterior-Posterior Alignment Perturbations," JPO Journal of Prosthetics and Orthotics, vol. 24, no. 4, pp. 160-174, 2012.

[58] E. S. Neumann, J. Brink, K. Yalamanchili et al., "Use of a load cell and forcemoment curves to compare transverse plane moment loads on transtibial residual limbs: a preliminary investigation," Prosthet Orthot Int, vol. 38, no. 3, pp. 253-262, Aug 6, 2013.

[59] E. S. Neumann, J. Brink, K. Yalamanchili et al., "Regression Estimates of Pressure on Transtibial Residual Limbs Using Load Cell Measurements of the Forces and
Moments Occurring at the Base of the Socket," JPO Journal of Prosthetics and Orthotics, vol. 25, no. 1, pp. 1-12, 2013.

[60] E. S. Neumann, K. Yalamanchili, J. Brink et al., "Transducer-based comparisons of the prosthetic feet used by transtibial amputees for different walking activities: a pilot study," Prosthet Orthot Int, vol. 36, no. 2, pp. 203-16, Jun, 2012.

[61] D. Dean, and C. G. Saunders, "A software package for design and manufacture of prosthetic sockets for transtibial amputees," IEEE Trans Biomed Eng, vol. 32, no. 4, pp. 257-62, Apr, 1985.

[62] W. Lee, L. Frossard, K. Hagberg et al., "Kinetics analysis of transfemoral amputees fitted with osseointegrated fixation performing common activities of daily living," Clinical Biomechanics, vol. 22, no. 6, pp. 665-673, 2007.

[63] S. R. Koehler, Y. Y. Dhaher, and A. H. Hansen, "Cross-validation of a portable, six-degree-of-freedom load cell for use in lower-limb prosthetics research," $J$ Biomech, vol. 47, no. 6, pp. 1542-1547, Apr 11, 2014.

[64] L. Frossard, and M. Pitkin, "Characterisation of prosthetic feet loading profile for transtibial boneanchored prostheses attached to osseointegrated fixation during daily activities," JPO (manuscript prepared for submission), 2018.

[65] M. S. Orendurff, "Literature Review of Published Research Investigating Microprocessor-Controlled Prosthetic Knees: 2010 - 2012," JPO: Journal of Prosthetics and Orthotics, vol. 25, no. 4S, 2013.

[66] E. Haggstrom, K. Hagberg, B. Rydevik et al., "Vibrotactile evaluation: osseointegrated versus socket-suspended transfemoral prostheses," J Rehabil Res Dev, vol. 50, no. 10, pp. 1423-34, 2013.

[67] P. Cherelle, V. Grosu, A. Matthys et al., "Design and Validation of the Ankle Mimicking Prosthetic (AMP-) Foot 2.0," IEEE Trans Neural Syst Rehabil Eng, vol. 22, no. 1, pp. 138-48, Jan, 2014.

[68] J. D. Miller, M. S. Beazer, and M. E. Hahn, "Myoelectric walking mode classification for transtibial amputees," IEEE Trans Biomed Eng, vol. 60, no. 10, pp. 2745-50, Oct, 2013.

[69] E. Zheng, L. Wang, K. Wei et al., "A noncontact capacitive sensing system for recognizing locomotion modes of transtibial amputees," IEEE Trans Biomed Eng, vol. 61, no. 12, pp. 2911-20, Dec, 2014. 
Fig 1. The ankle moment as a function of the ankle angle with computed stiffness during level walking for asymptomatic subjects (black disc, $\mathrm{K} 1$ and $\mathrm{K} 2$ ) and transfemoral amputees (black triangles, K). Adapted from [3] with permission from the publisher.

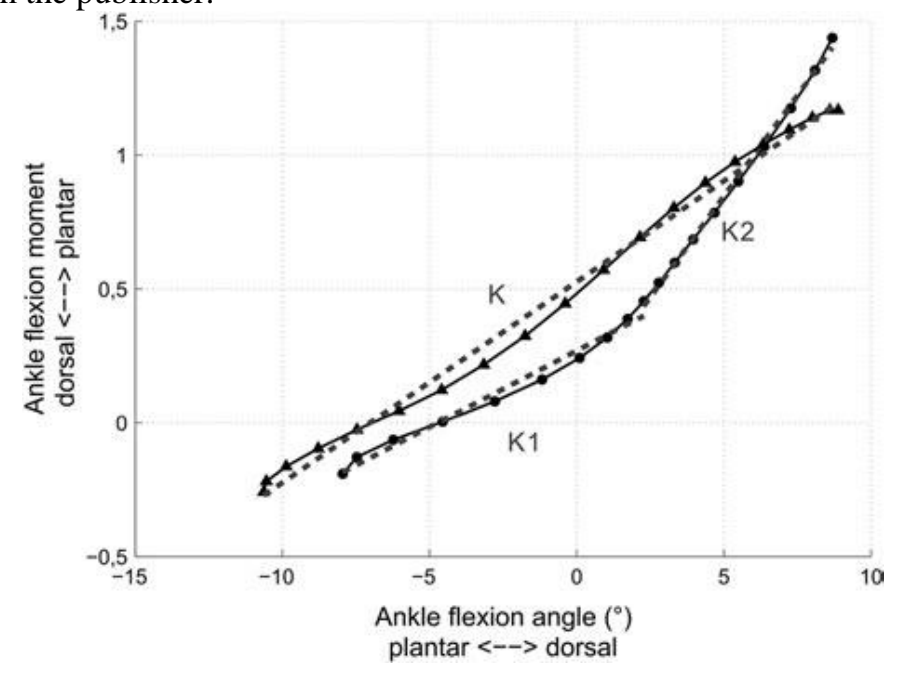

Fig 2. Example of long axes of the leg (LGL) and foot (LGF) used to determine ankle angle of dorsiflexion of the instrumented transtibial bone-anchored prosthesis attached to residuum (A) and percutaneous part of osseointegration fixation (B) including connector (C), transducer (D), pylon (E) and multi-axial rolling Free-Flow Foot (Ohio Willow Wood) (F) with anthropomorphic moments of dorsiflexion, inversion/eversion and axial rotation featuring screw for adjustment of initial stiffness (1), tibial surface of rolling contact (2), cushion (3) and base talar surface of rolling (4).

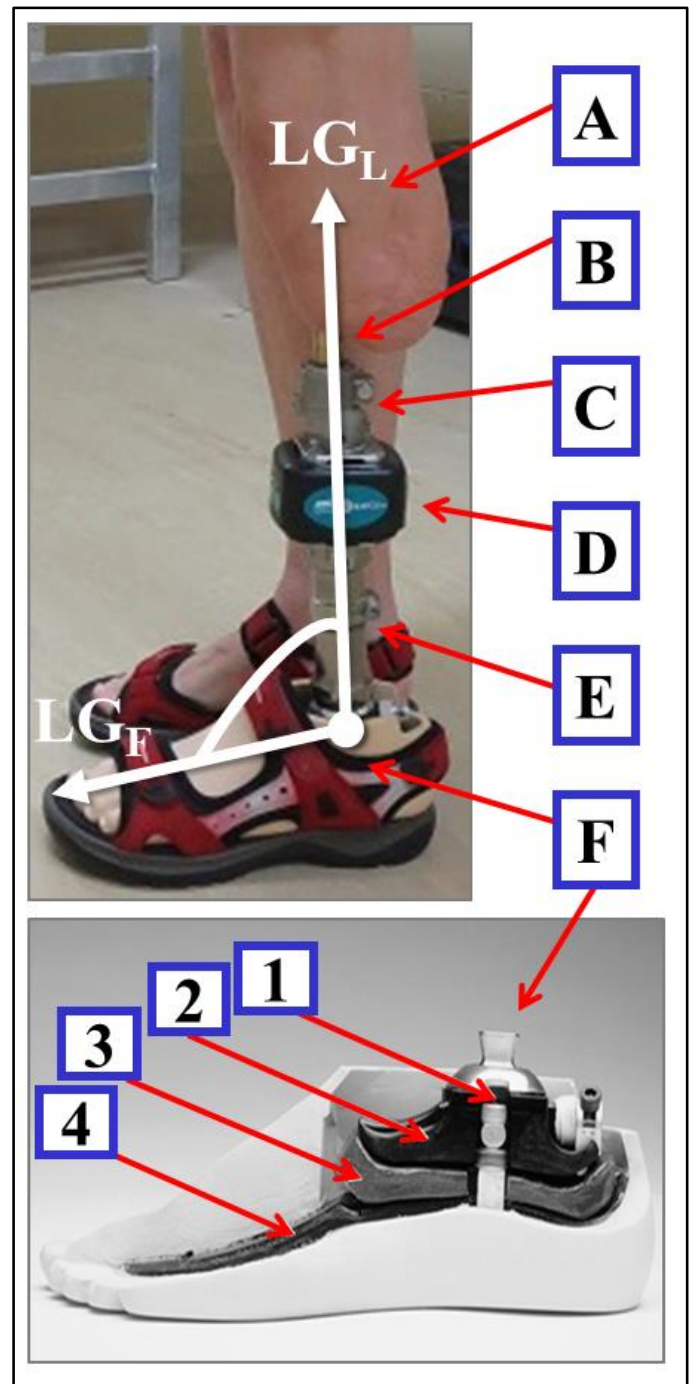


TABLE I. Overview of 12-step process for an automated characterization of stiffness profile including the shape of the moment-angle curve and magnitude of the stiffness of ankle joint fitted to a transtibial prosthesis

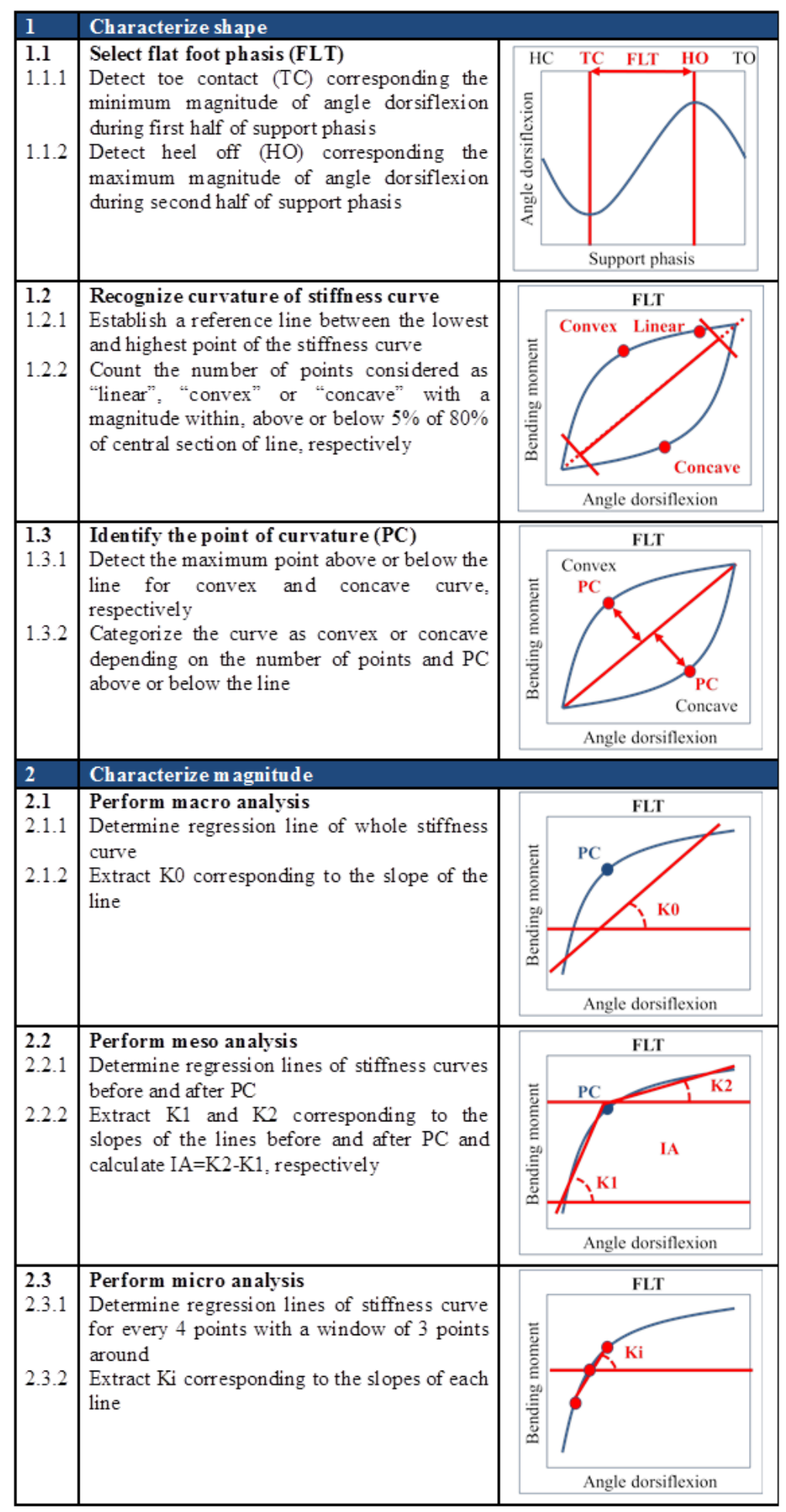


TABLE II. Individual and grouped demographics, amputation and prosthetic information including components of prosthesis fitted with usual and Free-Flow feet

\begin{tabular}{|c|c|c|c|c|c|}
\hline & & Participant 1 & Participant 2 & Participant 3 & Grouped \\
\hline \multicolumn{6}{|l|}{ Demographics } \\
\hline Gender & $(\mathrm{M} / \mathrm{F})$ & M & M & $\mathrm{F}$ & - \\
\hline Age & (yrs) & 38 & 69 & 67 & $58 \pm 17$ \\
\hline Height & $(\mathrm{m})$ & 1.92 & 1.78 & 1.58 & $1.76 \pm 0.17$ \\
\hline Mass & $(\mathrm{kg})$ & 109.12 & 81.74 & 59.52 & $83.46 \pm 24.84$ \\
\hline BMI & $(\mathrm{kg} / \mathrm{m} 2)$ & 29.080 & 25.123 & 23.293 & $25.832 \pm 2.958$ \\
\hline \multicolumn{6}{|l|}{ Amputation } \\
\hline Cause & & Other & Trauma & Trauma & - \\
\hline Side & $(\mathrm{L} / \mathrm{R})$ & $\mathrm{R}$ & $\mathrm{R}$ & L & - \\
\hline Time since amputatior & (yrs) & 9 & 5 & 32 & $15 \pm 15$ \\
\hline Time since OI & (yrs) & 2 & 2 & 3 & $2 \pm 1$ \\
\hline Length of leg & $(\mathrm{cm})$ & 46.94 & 42.67 & 37.28 & $42.3 \pm 4.84$ \\
\hline Length of residuum & $(\mathrm{cm})$ & 12.42 & 9.38 & 11.52 & $11.11 \pm 1.56$ \\
\hline Length of residuum & $(\% \mathrm{LoL})$ & 26 & 22 & 31 & $26 \pm 4$ \\
\hline \multicolumn{6}{|l|}{ Usual foot } \\
\hline Brand & & RUSH & Otto Bock & Otto Bock & - \\
\hline Model & & RUSH foot & Trias & Triton & - \\
\hline Footwear & & Running shoes & Running shoes & Sandals & - \\
\hline Foot size & $(\mathrm{cm})$ & 27 & 27 & 22 & $25 \pm 3$ \\
\hline \multicolumn{6}{|l|}{ Free-Flow foot } \\
\hline Brand & & & hio Willio Wood & & - \\
\hline Model & & & Free-Flow & & - \\
\hline Footwear & & Running shoes & Running shoes & Sandals & - \\
\hline Foot size & $(\mathrm{cm})$ & 27 & 26 & 24 & $26 \pm 2$ \\
\hline
\end{tabular}

TABLE III. Comparison of individual and grouped spatio-temporal gait characteristics with prosthesis fitted with usual and Free-Flow feet

\begin{tabular}{|c|c|c|c|c|c|c|c|c|}
\hline & \multicolumn{2}{|c|}{ Participant 1} & \multicolumn{2}{|l|}{ Participant 2} & \multicolumn{2}{|c|}{ Participant 3} & \multicolumn{2}{|l|}{ Grouped } \\
\hline Usual foot & $(\mathrm{N}=5)$ & & $(\mathrm{N}=5)$ & & $(\mathrm{N}=4)$ & & $(\mathrm{N}=14)$ & \\
\hline Cadence (Strides/min) & $40 \pm 1$ & $\mathrm{~L}$ & $52 \pm 1$ & $\mathrm{~L}$ & $40 \pm 2$ & $\mathrm{~L}$ & $44 \pm 6$ & $\mathrm{~L}$ \\
\hline \multicolumn{9}{|l|}{ Duration (s) } \\
\hline Gait cycle & $1.488 \pm 0.034$ & $\mathrm{~L}$ & $1.158 \pm 0.02$ & $\mathrm{~L}$ & $1.485 \pm 0.07$ & $\mathrm{~L}$ & $1.386 \pm 0.163$ & $\mathrm{~L}$ \\
\hline Support & $0.944 \pm 0.036$ & $\mathrm{~L}$ & $0.71 \pm 0.011$ & $\mathrm{~L}$ & $1.015 \pm 0.056$ & $\mathrm{~L}$ & $0.893 \pm 0.136$ & $\mathrm{~L}$ \\
\hline Swing & $0.545 \pm 0.009$ & $\mathrm{~L}$ & $0.449 \pm 0.018$ & $\mathrm{~L}$ & $0.471 \pm 0.036$ & $\mathrm{~L}$ & $0.492 \pm 0.049$ & $\mathrm{~L}$ \\
\hline \multicolumn{9}{|l|}{ Duration (\%GC) } \\
\hline Support & $63 \pm 1$ & $\mathrm{~L}$ & $61 \pm 1$ & $\mathrm{~L}$ & $68 \pm 2$ & $\mathrm{~L}$ & $64 \pm 3$ & $\mathrm{~L}$ \\
\hline Swing & $37 \pm 1$ & $\mathrm{~L}$ & $39 \pm 1$ & $\mathrm{~L}$ & $32 \pm 2$ & $\mathrm{~L}$ & $36 \pm 3$ & $\mathrm{~L}$ \\
\hline Free-Flow foot & $(\mathrm{N}=5)$ & & $(\mathrm{N}=4)$ & & $(\mathrm{N}=5)$ & & $(\mathrm{N}=14)$ & \\
\hline Cadence (Strides/min) & $45 \pm 1$ & $\mathrm{~L}$ & $51 \pm 1$ & $\mathrm{~L}$ & $41 \pm 1$ & $\mathrm{~L}$ & $46 \pm 4$ & $\mathrm{~L}$ \\
\hline \multicolumn{9}{|l|}{ Duration (s) } \\
\hline Gait cycle & $1.337 \pm 0.041$ & $\mathrm{~L}$ & $1.175 \pm 0.016$ & $\mathrm{~L}$ & $1.46 \pm 0.029$ & $\mathrm{~L}$ & $1.325 \pm 0.12$ & $\mathrm{~L}$ \\
\hline Support & $0.827 \pm 0.051$ & $\mathrm{~L}$ & $0.718 \pm 0.027$ & $\mathrm{~L}$ & $0.933 \pm 0.01$ & $\mathrm{~L}$ & $0.826 \pm 0.094$ & $\mathrm{~L}$ \\
\hline Swing & $0.51 \pm 0.018$ & $\mathrm{~L}$ & $0.458 \pm 0.012$ & $\mathrm{~L}$ & $0.527 \pm 0.032$ & $\mathrm{~L}$ & $0.499 \pm 0.036$ & $\mathrm{~L}$ \\
\hline \multicolumn{9}{|l|}{ Duration (\%GC) } \\
\hline Support & $62 \pm 2$ & $\mathrm{~L}$ & $61 \pm 1$ & $\mathrm{~L}$ & $64 \pm 2$ & $\mathrm{~L}$ & $62 \pm 2$ & $\mathrm{~L}$ \\
\hline Swing & $38 \pm 2$ & $\mathrm{~L}$ & $39 \pm 1$ & $\mathrm{~L}$ & $36 \pm 2$ & $\mathrm{~L}$ & $38 \pm 2$ & $\mathrm{~L}$ \\
\hline \multicolumn{9}{|c|}{ Difference (Free-Flow foot-Usual foot) } \\
\hline Cadence (Strides/min) & 5 & A & -1 & B & 1 & B & 2 & B \\
\hline \multicolumn{9}{|l|}{ Duration (s) } \\
\hline Gait cycle & -0.151 & A & 0.017 & B & -0.026 & B & -0.061 & B \\
\hline Support & -0.117 & A & 0.008 & B & -0.082 & B & -0.067 & B \\
\hline Swing & -0.035 & B & 0.009 & B & 0.056 & A & 0.007 & B \\
\hline \multicolumn{9}{|l|}{ Duration (\%GC) } \\
\hline Support & -2 & $\mathrm{~B}$ & 0 & B & -4 & B & -2 & B \\
\hline Swing & 2 & $\mathrm{~B}$ & 0 & B & 4 & A & 2 & B \\
\hline
\end{tabular}


TABLE IV. Comparison of individual and grouped characterization of stiffness profile including mean and standard deviation of shape and magnitude of moment-angle curves of usual and Free-Flow feet fitted to transtibial bone-anchored prosthesis

\begin{tabular}{|c|c|c|c|c|c|c|c|c|}
\hline & \multicolumn{2}{|l|}{ Participant 1} & \multicolumn{2}{|l|}{ Participant 2} & \multicolumn{2}{|c|}{ Participant 3} & \multicolumn{2}{|l|}{ Grouped } \\
\hline Usual foot & $(\mathrm{N}=5)$ & & $(\mathrm{N}=5)$ & & $(\mathrm{N}=4)$ & & $(\mathrm{N}=14)$ & \\
\hline \multicolumn{9}{|l|}{ Shape } \\
\hline \multicolumn{9}{|c|}{ Duration (\% DUR) } \\
\hline $\mathrm{HC}$ to $\mathrm{TC}$ & $13 \pm 6$ & $\mathrm{H}$ & $15 \pm 2$ & $\mathrm{~L}$ & $25 \pm 3$ & $\mathrm{~L}$ & $17 \pm 7$ & \\
\hline $\mathrm{TC}$ to $\mathrm{HO}$ & $71 \pm 6$ & $\mathrm{~L}$ & $63 \pm 5$ & $\mathrm{~L}$ & $57 \pm 3$ & $\mathrm{~L}$ & $64 \pm 8$ & \\
\hline $\mathrm{HO}$ to $\mathrm{TO}$ & $16 \pm 3$ & $\mathrm{~L}$ & $22 \pm 3$ & $\mathrm{~L}$ & $19 \pm 3$ & $\mathrm{~L}$ & $19 \pm 4$ & \\
\hline $\mathrm{PC}$ & $47 \pm 8$ & $\mathrm{~L}$ & $34 \pm 3$ & $\mathrm{~L}$ & $59 \pm 8$ & $\mathrm{~L}$ & $46 \pm 12$ & \\
\hline \multicolumn{9}{|c|}{ Curvature (\%FLT) } \\
\hline Linear & $5 \pm 4$ & & $5 \pm 5$ & & $8 \pm 13$ & & $6 \pm 7$ & \\
\hline Convex & $74 \pm 29$ & & $80 \pm 24$ & & $91 \pm 13$ & & $81 \pm 23$ & \\
\hline Concave & $19 \pm 25$ & & $14 \pm 18$ & & $0 \pm 0$ & & $12 \pm 19$ & \\
\hline \multicolumn{9}{|c|}{ Magnitude (Nm/Deg) } \\
\hline $\mathrm{K} 0$ & $4.966 \pm 0.813$ & $\mathrm{~L}$ & $3.843 \pm 0.947$ & $\mathrm{H}$ & $2.901 \pm 0.337$ & $\mathrm{~L}$ & $3.975 \pm 1.116$ & $\mathrm{H}$ \\
\hline K1 & $5.454 \pm 0.723$ & $\mathrm{~L}$ & $6.441 \pm 1.684$ & $\mathrm{H}$ & $3.679 \pm 1.440$ & $\mathrm{H}$ & $5.299 \pm 1.682$ & $\mathrm{H}$ \\
\hline $\mathrm{K} 2$ & $3.475 \pm 1.343$ & $\mathrm{H}$ & $2.019 \pm 0.420$ & $\mathrm{H}$ & $1.299 \pm 2.118$ & $\mathrm{H}$ & $2.333 \pm 1.585$ & $\mathrm{H}$ \\
\hline IA & $-1.978 \pm 1.477$ & $\mathrm{H}$ & $-4.423 \pm 1.670$ & $\mathrm{H}$ & $-2.380 \pm 3.476$ & $\mathrm{H}$ & $-2.966 \pm 2.369$ & $\mathrm{H}$ \\
\hline Free-Flow foot & $(\mathrm{N}=5)$ & & $(\mathrm{N}=4)$ & & $(\mathrm{N}=5)$ & & $(\mathrm{N}=14)$ & \\
\hline \multicolumn{9}{|l|}{ Shape } \\
\hline \multicolumn{9}{|c|}{ Duration (\%DUR) } \\
\hline $\mathrm{HC}$ to $\mathrm{TC}$ & $12 \pm 3$ & $\mathrm{H}$ & $12 \pm 0$ & $\mathrm{~L}$ & $13 \pm 4$ & $\mathrm{H}$ & $12 \pm 3$ & $\mathrm{H}$ \\
\hline $\mathrm{TC}$ to $\mathrm{HO}$ & $76 \pm 3$ & $\mathrm{~L}$ & $44 \pm 12$ & $\mathrm{H}$ & $61 \pm 10$ & $\mathrm{~L}$ & $61 \pm 15$ & \\
\hline $\mathrm{HO}$ to $\mathrm{TO}$ & $12 \pm 4$ & $\mathrm{H}$ & $44 \pm 12$ & $\mathrm{H}$ & $26 \pm 6$ & $\mathrm{H}$ & $26 \pm 15$ & $\mathrm{H}$ \\
\hline $\mathrm{PC}$ & $38 \pm 7$ & $\mathrm{~L}$ & $31 \pm 3$ & $\mathrm{~L}$ & $37 \pm 4$ & $\mathrm{~L}$ & $36 \pm 6$ & $\mathrm{~L}$ \\
\hline \multicolumn{9}{|c|}{ Curvature (\%FLT) } \\
\hline Linear & $5 \pm 2$ & & $7 \pm 8$ & & $11 \pm 5$ & & $8 \pm 6$ & \\
\hline Convex & $42 \pm 20$ & & $10 \pm 4$ & & $42 \pm 8$ & & $33 \pm 20$ & \\
\hline Concave & $52 \pm 20$ & & $80 \pm 10$ & & $44 \pm 12$ & & $57 \pm 21$ & \\
\hline \multicolumn{9}{|c|}{ Magnitude (Nm/Deg) } \\
\hline K0 & $2.699 \pm 0.250$ & $\mathrm{~L}$ & $2.910 \pm 0.403$ & $\mathrm{~L}$ & $2.315 \pm 0.341$ & $\mathrm{~L}$ & $2.622 \pm 0.396$ & $\mathrm{~L}$ \\
\hline K1 & $0.730 \pm 0.232$ & $\mathrm{H}$ & $1.489 \pm 0.303$ & $\mathrm{H}$ & $0.881 \pm 0.172$ & $\mathrm{~L}$ & $1.001 \pm 0.392$ & $\mathrm{H}$ \\
\hline $\mathrm{K} 2$ & $4.049 \pm 0.680$ & $\mathrm{~L}$ & $3.759 \pm 1.096$ & $\mathrm{H}$ & $3.254 \pm 0.967$ & $\mathrm{H}$ & $3.682 \pm 0.912$ & $\mathrm{H}$ \\
\hline IA & $3.319 \pm 0.679$ & $\mathrm{H}$ & $2.270 \pm 1.385$ & $\mathrm{H}$ & $2.373 \pm 1.076$ & $\mathrm{H}$ & $2.681 \pm 1.089$ & $\mathrm{H}$ \\
\hline
\end{tabular}

Difference (Free-Flow foot-Usual foot)

Shape

Duration (\%DUR)

$\begin{array}{lcccccccc}\text { HC to TC } & -2 & \text { A } & -3 & \text { A } & -12 & \text { A } & -5 & \text { A } \\ \text { TC to HO } & 5 & \text { B } & -19 & \text { A } & 4 & \text { B } & -3 & \text { B } \\ \text { HO to TO } & -3 & \text { A } & 22 & \text { A } & 8 & \text { A } & 7 & \text { A } \\ \text { PC } & -9 & \text { A } & -3 & \text { B } & -22 & \text { A } & -10 & \text { A }\end{array}$

Magnitude (Nm/Deg)

\begin{tabular}{lllllllll} 
K0 & -2.267 & $\mathrm{~A}$ & -0.934 & $\mathrm{~A}$ & -0.586 & $\mathrm{~A}$ & -1.353 & $\mathrm{~A}$ \\
$\mathrm{~K} 1$ & -4.724 & $\mathrm{~A}$ & -4.952 & $\mathrm{~A}$ & -2.798 & $\mathrm{~A}$ & -4.299 & $\mathrm{~A}$ \\
$\mathrm{~K} 2$ & 0.573 & $\mathrm{~A}$ & 1.740 & $\mathrm{~A}$ & 1.955 & $\mathrm{~A}$ & 1.349 & $\mathrm{~A}$ \\
$\mathrm{IA}$ & 5.297 & $\mathrm{~A}$ & 6.692 & $\mathrm{~A}$ & 4.753 & $\mathrm{~A}$ & 5.647 & $\mathrm{~A}$ \\
\hline
\end{tabular}


Fig 3. Mean and standard deviation of grouped angle of dorsiflexion and bending moment as well as shape and regression lines deriving from macro $(\mathrm{K} 0)$, meso $(\mathrm{K} 1, \mathrm{~K} 2)$ and micro $(\mathrm{Ki})$ analyses of overall moment-angle curves of usual $(\mathrm{N}=14)$ and Free-Flow $(\mathrm{N}=14)$ feet fitted to transtibial bone-anchored prostheses. HC: Heel contact, TC: Toe contact, HO: Heel off, TO: Toe off
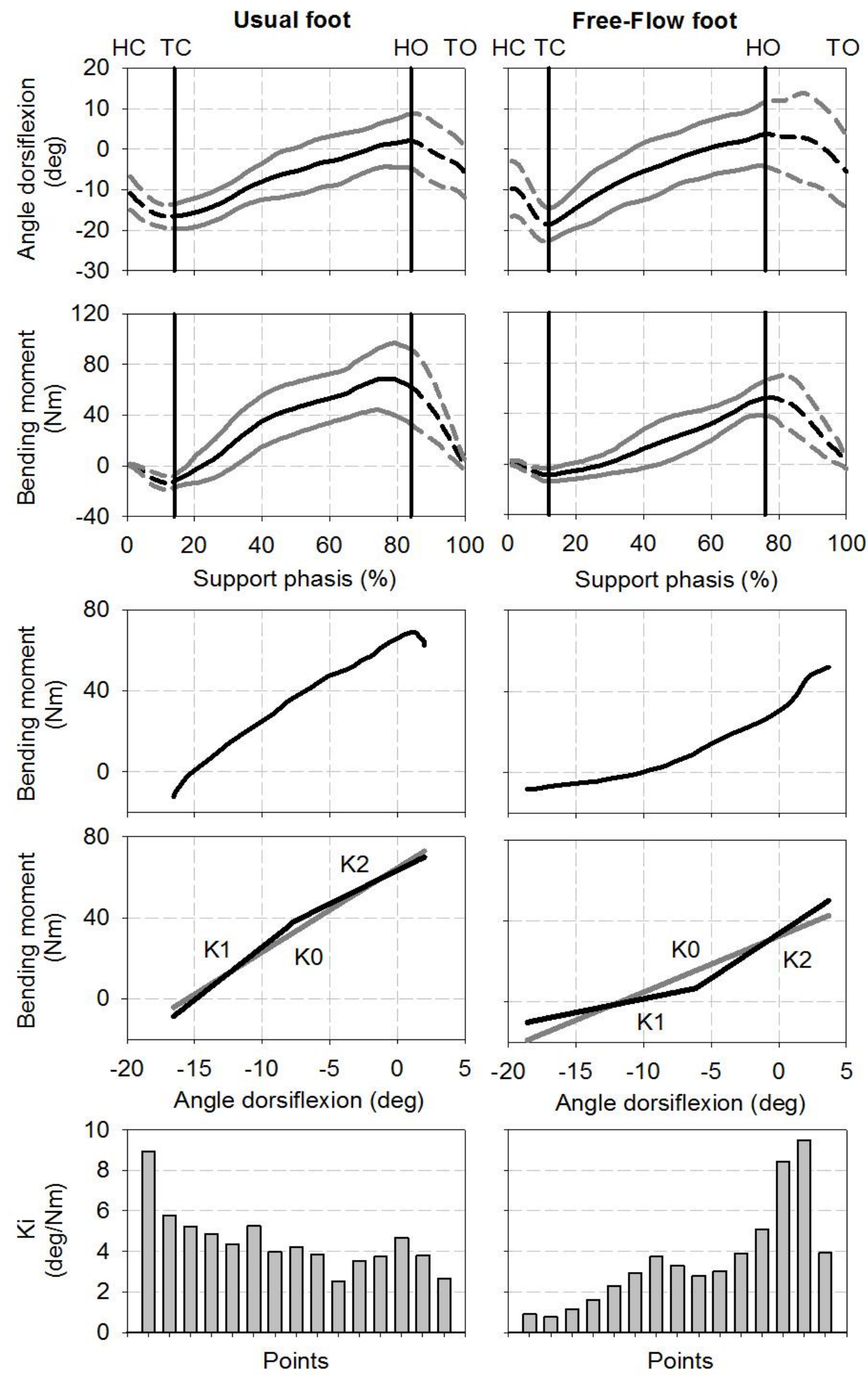